OPEN ACCESS

Edited by:

Matteo Angelo Fabris,

University of Turin, Italy

Reviewed by:

Jamel Hajij,

Tunis University, Tunisia

Veronica Velasco,

University of Milano-Bicocca, Italy

*Correspondence:

Weijie Meng

sdlduly@163.com

Bingyuan Liu

bingyuanld@126.com

Specialty section:

This article was submitted to

Educational Psychology,

a section of the journal

Frontiers in Psychology

Received: 26 October 2021

Accepted: 20 December 2021

Published: 10 January 2022

Citation:

Liu L, Meng W and Liu B (2022)

The Mediating Role of Social Support in the Relationship Between Parenting

Styles and Adolescent Drug Abuse

Identification.

Front. Psychol. 12:802408. doi: 10.3389/fpsyg.2021.802408

\section{The Mediating Role of Social Support in the Relationship Between Parenting Styles and Adolescent Drug Abuse Identification}

\author{
Li Liu ${ }^{1,2}$, Weijie Meng ${ }^{1,2 *}$ and Bingyuan Liu ${ }^{3 *}$ \\ ${ }^{1}$ School of Educational Science, Ludong University, Yantai, China, ${ }^{2}$ Institute for Education and Treatment of Problematic \\ Youth, Ludong University, Yantai, China, ${ }^{3}$ School of Marxism, Shandong Youth University of Political Science, Jinan, China
}

Adolescent drug abuse is a social issue of global concern, causing a serious burden of diseases for individuals, families and society. To design effective prevention and intervention strategies for adolescent drug abusers, the predictive factors associated with drug abuse must be quantified and assessed. This study explores the similarities and differences between the parenting styles of adolescent drug abusers and non-drug abusers and applies a structural equation model to analyze the mechanisms involved between parenting styles, social support and adolescent drug abuse identification. Data were derived from adolescent drug abusers $(n=363)$ and non-drug abusers ( $n=229$ ) between the ages of 18 and 35 in China, and the data were collected and analyzed by SPSS 26 and AMOS 24. The results show that parenting styles significantly predict adolescent drug abuse identification, and different parenting styles have different influencing mechanisms, which further indicates that poor parenting styles are a risk factor for adolescent drug abuse. Additionally, social support plays a mediating role between parenting styles and drug abuse identification $\left(x^{2} / \mathrm{df}=4.52\right.$, $\mathrm{CFI}=0.939, \mathrm{TLI}=0.914, \mathrm{RMSEA}=0.077, \mathrm{IFI}=0.939, \mathrm{PCFI}=0.671)$. The specific pathways involved are as follows: Paternal parenting style $\rightarrow$ Social support $\rightarrow$ Drug abuse identification and Maternal parenting style $\rightarrow$ Social support $\rightarrow$ Drug abuse identification. However, beyond this, the mediation model of social support shows good adaptability and stability between adolescent drug abusers and non-drug abusers. Since parenting styles and social support are important predictors of adolescent drug abuse, the importance of integrating family-social support antidrug programs into adolescent prevention and intervention strategies should be considered.

Keywords: adolescent drug abuse identification, parenting styles, social support, mediating role, prevention and intervention strategies

\section{INTRODUCTION}

Drug abuse is a social issue of global concern, and an increase in the number of drug abusers has placed a serious burden of disease on individuals, families and society (Kepple, 2017; Perruci et al., 2021). According to statistics, approximately 279 million people worldwide used drugs in 2020, representing a $22 \%$ increase from the number of drug users in 2010 (UNODC, 2021). For drug 
abusers, first exposed to smoke and alcohol occurs between the ages of 12 and 14 (Malta et al., 2011). These findings are worrisome because early exposed to drugs increases the likelihood of physical illness and social risk in adolescents. The findings are also concerning to educators and others who work with adolescents and call for prevention campaigns targeting drug abuse identification (James et al., 2013; Thompson et al., 2013; Hall et al., 2016). Drug abuse identification mainly refers to an individual's effective or valuable evaluation of drug abuse, emphasizing identification with drug abuse events. Furthermore, drug abuse identification is essentially a value identification of drug abuse events. Therefore, in preventing adolescent drug abuse, it is important to identify and focus on the predictors of protection and risk associated with early exposed to drugs (Degenhardt et al., 2016; Dumas et al., 2020). Additionally, social development theorists believe that the protection and risk factors of adolescent drug abuse are connected to the first socialization model-learning behavior (Cambron et al., 2019). Furthermore, social development theorists believe that family is an influential domain for drug use among adolescents. Adolescents acquire the values, attitudes, cognitive styles and behavioral habits of others based on observation and learning in their households, especially through the continuing influence of parenting styles on the development of their positive and negative behaviors (Karaer and Akdemir, 2019). For instance, as reported by Lippold et al. (2014) and Valente et al. (2019), parenting styles are strong predictors of drug abuse among adolescents.

The classification of parenting styles can be traced back to the work of Baumrind (2013), which is used to explore parents' responses to adolescents' attitudes or orientations in various situations or surroundings, mainly in terms of values, attitudes toward parenting styles, development concepts and parenting educational practices for adolescents (Takahara et al., 2017; Clayborne et al., 2021). Moreover, stable parenting styles involve long-term maintenance of values, beliefs, attitudes, and behaviors (Dembo et al., 2015). Parenting styles entail attitudes and behaviors toward adolescents and provide an emotional environment for parent-child relationships and adolescent development. In addition, Schaefer proposed acceptancerejection, psychological autonomy-psychological control, and firm control-lax control approaches based on children's evaluation of their own parents' parenting styles (Matejevic et al., 2014). However, Perris and Andersson (2000) observed that the aforementioned dimensions do not cover all facets of parenting styles. Based on this, the authors constructed a new model and identified four factors that affect parenting styles, including rejection, overprotection, emotional warmth and the favoring subject (Asbrand et al., 2017), which are also the main facets of parenting styles examined in this study.

Parenting styles are also a major focus of adolescent drug abuse identification research. Researchers have found that low levels of support, rejection, and overprotective parenting styles are related to elevated rates of adolescent drug abuse. In contrast, warm understanding and a high level of support can reduce dependence and protect against adolescent drug abuse (Matejevic et al., 2014; Garcia et al., 2020). In addition, the relationship between parenting styles and drug abuse varies across countries depending on culture, but the findings remain relevant in that parenting styles have effects independent of the country investigated (Valente et al., 2017). For instance, some researchers have found that positive parenting styles are protective against adolescent drug abuse in Europe, whereas parental supervision and control are more important than supportive and warm parenting styles in Brazil (Ribeiro et al., 2013; Calafat et al., 2014; Sanchez et al., 2018). Therefore, to improve the prevention and intervention strategies of adolescent drug abusers, the development of parenting styles in accordance with national cultures is crucial.

Despite the evidence for the roles of parenting styles as risk and protective factors, researchers have ignored the mediating effect of parenting styles on adolescent drug abuse identification. Moreover, most studies have tended to examine the relationship between parenting styles and drug abuse identification and have not captured the complexity of the patterns and mechanisms of action involved (Varvil-Weld et al., 2014; Martínez-Loredo et al., 2016; Özdemir and Koutakis, 2016; Reis et al., 2020). Bronfenbrenner identified the family system as an important "microsystem" in which individuals are closely connected that affects the development of individuals and other systems. Such development is also interactive (Guy-Evans, 2020). Moreover, Bronfenbrenner indicated that the matching of microsystems serves as a significant basis for family to play a positive role, especially for a social ecosystem closely linked to the family microsystem (Morse et al., 2014). Social support within the social ecosystem has a strong impact on adolescent drug abuse and is considered to be one of the most important factors in promoting health (Buttram et al., 2013; Holt-Lunstad and Uchino, 2015). Social support includes access to information, material assistance, planning, health advice, and emotional support. Social support serves as a source of information for family, friends, classmates and neighbors, and high-quality social support is of great value in moderating emotions emerging in response to negative life events and in promoting wellbeing (Rapee et al., 2015; Uchino et al., 2018; Attar-Schwartz et al., 2019). Barra stated that social support, as a general factor contributing to improved stability, is conducive to a more positive perception of one's surrounding, a better use of personal and social resources, and higher adolescent emotional intelligence (Azpiazu et al., 2015; Gázquez et al., 2016). Barra also indicated that social support is significantly correlated with illicit drug use by adolescents and is a strong predictor of a variable called "Tendency." Additionally, Birtel et al. (2017) demonstrated that social support received by drug abusers influences illicit drug abuse and relapse after treatment. Furthermore, social support has a positive effect in maintaining the physical, emotional, and mental health of drug abusers, reducing the tendency to use illicit drugs (Mo et al., 2020). In conclusion, parenting styles are an important family-related factor affecting adolescent drug abuse identification, but this relationship lacks process exploration on the possible intermediate link between them, namely, social support. In addition, social support and parenting styles play moderating roles in their relationship with drug abuse (Rudolph et al., 2012; Go et al., 2016; Massah et al., 2017), 
but scarce studies have assessed the interactions of these moderating effects.

The aim of this study was to explore and analyze the effects of parenting styles and social support on adolescent drug abuse identification. Associated relationships and mechanisms, as well as protective and risk factors involved in drug abuse identification, were investigated. Additionally, differences in the effects of parenting styles on adolescent drug abusers and non-drug abusers were analyzed. Based on this, we propose four hypotheses. First, the parenting styles of parents of drug abusers are more negative than those of adolescent non-drug abusers. Second, parenting styles are significantly correlated with adolescent drug abuse identification. Third, parenting styles influence adolescent drug abuse identification based on the mediating role of social support. Finally, the mediating role of social support has excellent structural stability for both adolescent drug abusers and non-drug abusers. This work provides a practical and theoretical basis for integrating parenting styles and social support into antidrug strategies.

\section{MATERIALS AND METHODS}

\section{Participants and Survey Procedures}

The purpose of this study was to evaluate the influence of parenting styles and social support on adolescent drug abuse identification. The participants (ages 18-35; $M=28.5$, $S D=3.93)$ included 363 adolescent drug abusers $(49.0 \%$ males) from hospitals qualified for drug rehabilitation in Heilongjiang Province and compulsory drug rehabilitation centers in Shandong Province, China, and 229 adolescent nondrug abusers (48.0\% males) participating from all walks of life throughout China. Among the adolescent drug abusers, the proportion of first exposed to drugs in different age groups was $14.3 \%$ (ages 16), 16.5\% (ages 16-18), 47.9\% (ages 18-25), and $21.3 \%$ (ages 25-35), respectively. The study was completed in 2020 .

The participants of this questionnaire agreed to analyze and report on the information they provided in the survey. The procedure was divided into two stages. In the first stage, 363 adolescent drug abusers were evaluated by questionnaire and supervised by relevant staff. Moreover, prior to the completion of the survey, the researchers and relevant staff explained the purpose of the questionnaire and the more difficult questions and offered to answer questions throughout the process. Additionally, during the survey, administered by researchers in the quiet classroom, without the presence of the relevant managers to eliminate any sense of compulsion and the questionnaire was completed within approximately 3060 min depending on the participants' personal abilities, then, each de-identified questionnaire was placed in a folder. In the second stage, a random sample of 229 adolescent nondrug abusers (ages 18-35) was selected. The questionnaire followed principles of convenience sampling, was electronic, and presented challenging questions and topic explanations online after questions were answered. Gifts were offered to participants in the study.

\section{Measures and Instruments}

According to the purposes of this study, basic information on population variables (age, sex, age upon first exposure to drugs, etc.) was included as well as the basic measurement indicators for adolescent drug abuse identification, parenting styles, and social support.

\section{Drug Abuse Identification}

The drug abuse identification scale developed by Weng (2020) was adopted. The scale includes five items designed to represent adolescent drug abuse identification by measuring adolescents' understanding of drug knowledge, harm from drugs, and drug cognition. The scale was scored on a five-point scale with 1 meaning "never" and 5 meaning "always." The answers to all questions were summed to obtain an overall score. The higher the score was, the higher the adolescent drug abuse identification level $(\alpha=0.954)$.

\section{Parenting Styles}

The EMBU scale described in C. Perris was used to assess parenting styles, including maternal and paternal parenting styles. In the above work, 23 countries were studied for depression, personality disorders, criminal behavior, drug abuse behavior and other psychological behaviors with high reliability and validity (Chen et al., 2020). Based on this study, the revised scale includes 115 items $(\alpha=0.957)$, among which the subscale for paternal parenting styles has 6 dimensions [with 58 items $(\alpha=0.920)$ ], including emotional warmth and understanding ( $\alpha=0.904)$, punishment and severity $(\alpha=0.916)$, excessive interference ( $\alpha=0.743$ ), favoriting subject ( $\alpha=0.794)$, rejection and denial $(\alpha=0.816)$, and overprotection $(\alpha=0.708)$. The maternal parenting style scale has 5 dimensions [with 57 items $(\alpha=0.928)$ ], including emotional warmth and understanding ( $\alpha=0.920)$, punishment and severity $(\alpha=0.903)$, excessive interference and overprotection $(\alpha=0.798)$, favoriting subject $(\alpha=0.736)$, and rejection and denial $(\alpha=0.854)$. The scale adopts a four-point scoring method where 4 represent "always" and 1 represent "never." According to the corresponding scoring method, the dimensions of parenting styles were obtained.

\section{Social Support}

Social support was measured based on the self-rating scale compiled, which includes the three dimensions [with 10 items $(\alpha=0.77)$ ] of subjective support, objective support and support utilization degree (Song and Fan, 2013; Ke et al., 2019). The 4 items of subjective support reflect adolescents' emotional experiences of and satisfaction with feeling respected, supported and understood. In addition, the 3 items of objective support measure the degree to which adolescents believe that they actually receive support, including direct assistance and social support. The support utilization degree of social support includes 3 items, which reflect the utilization degree of social support by adolescents. The Cronbach's alpha values of each dimension in this study were $0.65 \sim 0.71$.

SPSS 26 was used for data processing, independent sample t-test, descriptive statistics, correlation analysis and data mining. AMOS 24 was used to construct a structural equation model 
to isolate random measurement errors from potential variables and increase explanatory power. Model fit parameters were set by the advocates of the structural equation model and should satisfy: $\chi^{2} / \mathrm{df}<5$, SRMR $<0.05$, CFI $>0.9$, TLI $>0.9$, RMSEA $<0.08$, IFI $>0.9$, and PCFI $>0.5$ (Mueller and Hancock, 2019; Abbas et al., 2021). Based on the structural equation model, the bootstrap method was used to analyze the significance of the effect of parenting styles on drug abuse identification.

\section{RESULTS}

\section{Control and Test of Common Method Deviation}

Since all the variables of this study were measured by subject selfreports, anonymous answers and partial item reverse measures were adopted to control common deviation during measurement (Liu et al., 2021). In addition, the Harman single-factor test was applied to the exploratory factor analysis. The unrotated exploratory factor results show 37 factor characteristics with values of greater than 1 , and the maximum factor variance explanation rate was measured as $18.796 \%$, which is far less than the critical standard of $40 \%$. Therefore, no serious common method deviation was identified.

\section{Difference Tests of All Study Variables Between Adolescent Drug Abusers and Non-drug Abusers}

An independent sample $t$-test was used to compare the adolescent non-drug abusers and adolescent drug abusers in terms of parenting styles, social support, and drug abuse identification. As shown in Table 1, significant differences were found between the adolescent drug abusers and non-drug abusers in terms of maternal and parental overprotection, social support, and drug abuse identification $(p<0.001)$. Additionally, scores for excessive interferences, favoring subject, rejection and denial, and overprotection from fathers in adolescent drug abusers were significantly higher than those in adolescent non-drug abusers $(p<0.001$ or $p<0.05)$, whereas the scores for overprotection and excessive interference, rejection and denial, and punishment and severity from mothers were significantly higher in adolescent drug abusers than in the control group $(p<0.001$ or $p<0.05)$. Furthermore, the results show that the scores for objective support and social support utilization degree in drug abusers were significantly lower than those of adolescent non-drug abusers $(p<0.001)$. The score for drug abuse identification among adolescent drug abusers was significantly higher than that of the adolescent non-drug abusers $(p<0.001)$, confirming that drug abuse identification affects adolescent drug abuse.

\section{Correlation Analysis of All Study Variables}

Pearson product-moment correlations (Emerson, 2015) were used to calculate the correlation coefficients between parenting styles, social support and drug abuse identification as shown in Table 2. The results show that adolescent drug abuse identification was significantly negatively correlated with social support $(r=-0.273)$ and significantly positively correlated with all facets of maternal $(r=0.140)$ and paternal $(r=0.145)$ parenting styles. In addition, we found a significant negative correlation between social support and parenting styles $(-0.167 \leq r \leq-0.162)$, whereas paternal parenting styles had a significant positive correlation with maternal parenting styles $(r=0.285)$. The results were compared to those of previous studies and show that drug abuse identification was related to maternal and paternal parenting styles and social support. Since many variables were significantly correlated, this laid a foundation for analyzing the effects of parenting styles on

TABLE 1 | Difference tests of all study variables for adolescent drug abusers and non-drug abusers.

\begin{tabular}{|c|c|c|c|c|}
\hline Variables & & $\begin{array}{l}\text { Adolescent drug abusers } \\
\qquad(N=363) M \pm S D\end{array}$ & $\begin{array}{c}\text { Adolescent non-drug } \\
\text { abusers }(N=229) M \pm S D\end{array}$ & $t$ \\
\hline \multirow[t]{6}{*}{ Paternal parenting style } & Emotional warmth and understanding & $39.316 \pm 11.659$ & $40.995 \pm 11.292$ & -1.663 \\
\hline & Punishment and severity & $18.368 \pm 7.328$ & $18.569 \pm 7.048$ & -0.288 \\
\hline & Excessive interference & $19.850 \pm 5.254$ & $18.768 \pm 4.785$ & $2.470^{*}$ \\
\hline & Favoriting subject & $10.158 \pm 2.898$ & $9.536 \pm 2.711$ & $2.487^{*}$ \\
\hline & Rejection and denial & $9.678 \pm 3.871$ & $8.901 \pm 3.399$ & $2.446^{\star}$ \\
\hline & Overprotection & $12.850 \pm 3.419$ & $11.864 \pm 3.036$ & $3.485^{\star \star \star}$ \\
\hline \multirow[t]{5}{*}{ Maternal parenting style } & Emotional warmth and understanding & $39.894 \pm 12.418$ & $41.456 \pm 11.666$ & -1.445 \\
\hline & Overprotection and excessive interference & $34.855 \pm 8.075$ & $31.589 \pm 6.367$ & $5.250^{\star \star \star}$ \\
\hline & Rejection and denial & $12.904 \pm 5.038$ & $11.868 \pm 4.127$ & $2.640^{\star \star}$ \\
\hline & Punishment and severity & $13.266 \pm 5.712$ & $12.232 \pm 4.152$ & $2.466^{\star}$ \\
\hline & Favoriting subject & $9.183 \pm 3.143$ & $9.161 \pm 2.251$ & 0.096 \\
\hline \multirow[t]{3}{*}{ Social support } & Subjective support & $22.253 \pm 5.666$ & $22.816 \pm 5.883$ & -1.157 \\
\hline & Objective support & $8.132 \pm 3.452$ & $10.083 \pm 3.95$ & $-6.139^{\star \star \star}$ \\
\hline & Support utilization degree & $6.812 \pm 2.036$ & $8.009 \pm 2.366$ & $-6.319^{\star \star *}$ \\
\hline Drug abuse identification & Drug abuse identification & $15.981 \pm 4.753$ & $14.38 \pm 5.213$ & $3.843^{\star \star \star}$ \\
\hline
\end{tabular}

Significance levels are indicated by *(for $p<0.05)$, **(for $p<0.01)$, and ${ }^{* * *}$ (for $\left.p<0.001\right)$. 
TABLE 2 | Correlations, means, and standard deviations of the main study variables.

\begin{tabular}{|c|c|c|c|c|c|c|}
\hline Variables & $M$ & $S D$ & Drug abuse identification & Social support & Paternal parenting style & Maternal parenting style \\
\hline Drug abuse identification & 3.072 & 0.999 & 1 & & & \\
\hline Social support & 2.612 & 0.639 & $-0.273^{\star \star}$ & 1 & & \\
\hline Paternal parenting style & 1.821 & 0.499 & $0.145^{\star \star}$ & $-0.162^{\star \star}$ & 1 & \\
\hline Maternal parenting style & 1.731 & 0.546 & $0.140^{\star \star}$ & $-0.167^{\star \star}$ & $0.285^{\star \star}$ & 1 \\
\hline
\end{tabular}

Significance levels are indicated by ${ }^{* *}($ for $p<0.01)$.

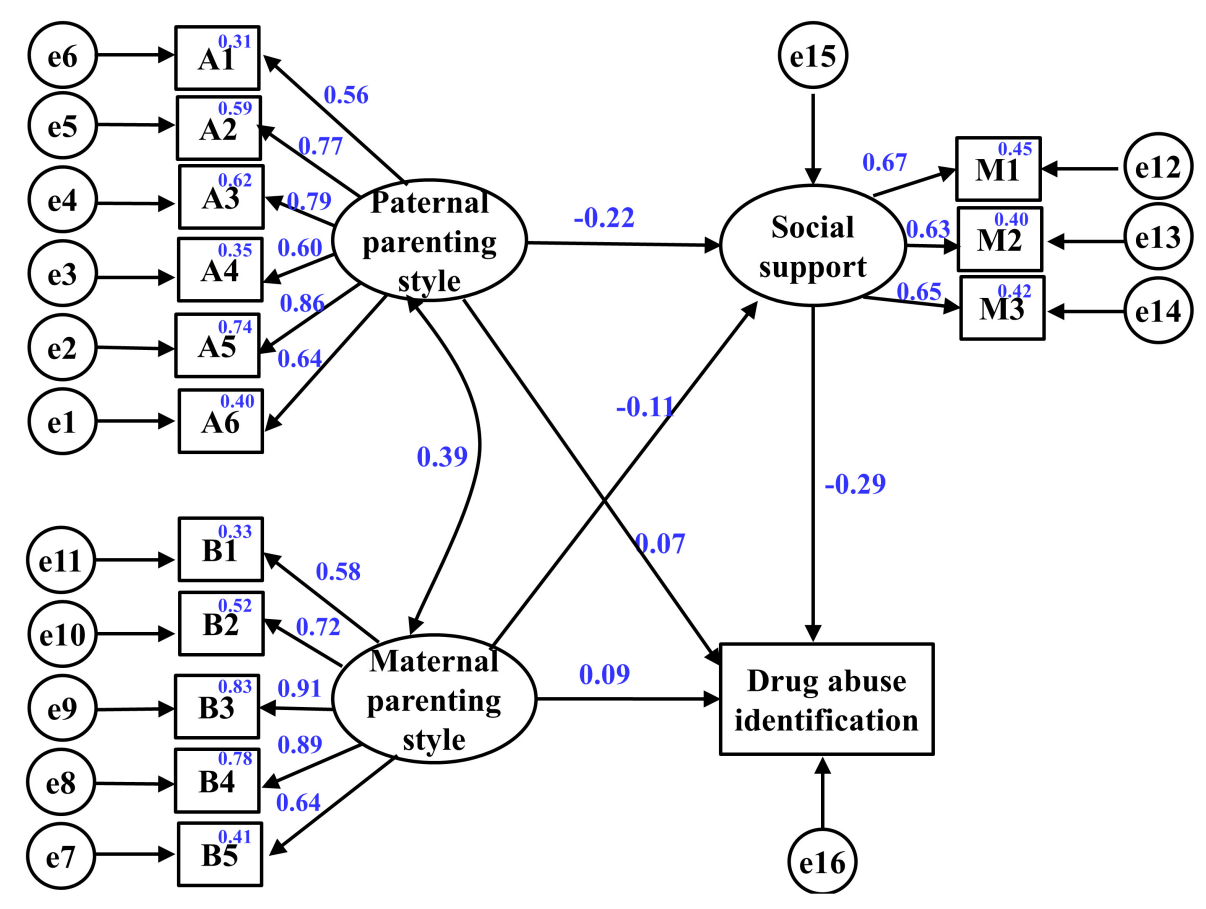

FIGURE 1 | Structural equation model representing the effects of parenting styles, including maternal and paternal parenting styles, and social support on adolescent drug abuse identification.

adolescent drug abuse identification and the mediating roles of social support.

\section{Measurement Model}

First, the fitting degree of the structural model must be tested. The three latent variables in the model are assumed to include multiple factors, and each factor involves multiple projects. Thus, to reduce study variable errors, the projects were packaged first, and the project mean of each factor was taken as the new index of each latent variable. Specifically, the mean of each factor for parenting styles, social support, and drug abuse identification, accounting for 15 factors, was used as a new indicator of the latent variables. According to the theoretical basis and research hypothesis of this study, paternal and maternal parenting styles were set as independent variables, social support was set as a mediating variable, and drug abuse identification was set as a dependent variable to construct the structural equation model (Figure 1). Confirmatory factor analysis results show that the measurement model has a good fit: $\chi^{2} / \mathrm{df}=4.520, \mathrm{CFI}=0.939$, $\mathrm{TLI}=0.914, \mathrm{RMSEA}=0.077, \mathrm{SRMR}=0.046, \mathrm{IFI}=0.939$, PCFI $=0.671$. However, the standardized factor loads of each index in the model range between 0.555 and 0.914 and above 0.6. Since the load of each factor is greater than 0.4 , the structural model shows "goodness of fit" and high structural validity.

\section{Structural Model: Linking Maternal and Paternal Parenting Styles, Social Support, and Drug Abuse Identification}

The measurement model includes the variance and covariance between all latent variables in the model. Therefore, the path coefficient between indicators can be estimated by calculating the variance and covariance of variables, and the recursive form was generally adopted in the selection of models. AMOS was used to calculate the path coefficient as described in Table 3. The results indicate that among the independent variables, maternal $(\beta=0.200, p>0.05)$ and paternal $(\beta=0.129, p>0.05)$ parenting styles did not directly predict drug abuse identification. The $\beta$ coefficient of social support to drug abuse identification is $0.629(p<0.001)$, indicating that social support had a reverse predictive effect on drug abuse identification. In addition, Table 3 shows that both maternal $(\beta=-0.111, p<0.05)$ and paternal 
TABLE 3 | Path coefficients between maternal and paternal parenting styles, social support, and drug abuse identification.

\begin{tabular}{|c|c|c|c|c|}
\hline Paths & Estimate & SE & CR & $P$ \\
\hline $\begin{array}{l}\text { Paternal parenting style } \rightarrow \\
\text { Social support }\end{array}$ & -0.178 & 0.047 & -3.769 & 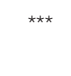 \\
\hline $\begin{array}{l}\text { Maternal parenting style } \rightarrow \\
\text { Social support }\end{array}$ & -0.111 & 0.038 & -1.926 & * \\
\hline $\begin{array}{l}\text { Paternal parenting style } \rightarrow \\
\text { Drug abuse identification }\end{array}$ & 0.129 & 0.085 & 1.526 & 0.127 \\
\hline $\begin{array}{l}\text { Maternal parenting style } \rightarrow \\
\text { Drug abuse identification }\end{array}$ & 0.200 & 0.103 & 1.950 & 0.051 \\
\hline $\begin{array}{l}\text { Social support } \rightarrow \text { Drug } \\
\text { abuse identification }\end{array}$ & -0.629 & 0.118 & -5.318 & $\star \star \star$ \\
\hline
\end{tabular}

Significance levels are indicated by *(for $p<0.05)$ and ${ }^{* * *}$ (for $\left.p<0.001\right)$.

$(\beta=-0.178, p<0.001)$ parenting styles had a significant reverse effect on social support.

\section{Bootstrap Test of Path Effect Size of Structural Model}

The non-parametric bootstrap method was used to test the significance of two indirect paths (I1 and I2) and two direct paths (D3 and D4) with a self-sampling value of 5,000 as shown in Table 4, which lists two indirect paths in the model: (I1) Paternal parenting style $\rightarrow$ Social support $\rightarrow$ Drug abuse identification. The effect value of this path is 0.062 ( $\mathrm{SE}=0.018, p<0.001,95 \%$ CI $[0.032,0.103])$, indicating that under social support, paternal parenting styles can predict adolescent drug abuse behavior. (I2) Maternal parenting style $\rightarrow$ Social support $\rightarrow$ Drug abuse identification. The effect value of this path is 0.031 ( $\mathrm{SE}=0.017$, $p=0.036$ and $p<0.05,95 \%$ CI $[0.002,0.069])$, demonstrating that maternal parenting styles also predict adolescent drug abuse behavior through social support, which further proves the indirect influence of parenting styles on adolescent drug abuse identification. However, in the direct path (D3 and D4) of parenting styles to drug abuse identification, all of the $p$-values are greater than 0.05 , and $95 \%$ CI values include 0 , indicating that parenting styles have no significant direct predictive effect on drug abuse identification. In conclusion, social support plays a fully mediating role in the influence of maternal and paternal parenting styles on drug abuse identification.

\section{Multi-Group Analysis of the Mediation Model Considering Social Support as a Mediating Variable}

Although the aforementioned studies prove the mediating role of social support between parenting styles and drug abuse identification, the mediation model constructed can only be generalized for the overall sample. Since our samples include adolescent drug abusers and non-drug abusers, a multi-group analysis of the mediation model was needed to further verify the model's suitability for the two types of groups. A confirmatory factor analysis of the multi-group samples is shown in Table 5 and Figure 2. Table 5 shows a good fit between the models of adolescent drug abusers and non-drug abusers $\left(\chi^{2} / \mathrm{df}<5\right)$. Furthermore, the difference values of the fit index factors, including IFI, TLI, GFI, AGFI, and RMSEA, are less than 0.05 , indicating no significant differences between the initial model and restricted model (Figure 2); that is, we found no significant differences between adolescent drug abusers and nondrug abusers in this model, and the model exhibited a certain level of stability. In conclusion, the mediation model of adolescent drug abuse is also applicable to adolescent non-drug abusers and can be extended to adolescent non-drug abusers, providing further evidence of the accuracy of the mediation model of social support for adolescent non-drug abusers. Additionally, the structural model provides a theoretical basis and application guidance for adolescent drug abuse prevention and intervention.

\section{DISCUSSION}

Adolescent drug abuse problems have been widely studied (Tremblay et al., 2020; Trucco, 2020), especially in relation to parenting styles, which have a profound influence on adolescent drug abuse. The relationships and mechanisms between parenting styles and adolescent drug abuse identification in China were investigated. The present study finds a significant positive correlation between poor parenting styles and drug abuse identification. The poorer parenting styles are used, the higher the level of drug abuse identification is, which is consistent with the results of previous studies (Becoña et al., 2012; Irles et al., 2013; Zhang et al., 2020; Zhang and Demant, 2021), whereas the mediating mechanism of the relationship remains largely unknown. This study explored the mechanisms of the relationships between parenting styles, such as maternal and paternal parenting styles, and drug abuse identification based on social support. The present study shows that the influence of parenting styles on adolescent drug abuse identification is realized through the mediating role of social support.

\section{Effect of Parenting Styles on Adolescent Drug Abuse Identification}

The results show that parenting styles, including maternal and paternal parenting styles, could significantly predict adolescent drug abuse behavior (Patte et al., 2017). Different family backgrounds and parenting styles have different effects on adolescent drug abuse, but this further proves that poor parenting styles are a risk factor for adolescent drug abuse (FernandezHermida et al., 2012; Hummel et al., 2013; Zrour et al., 2021). This study concludes that risk factors for parenting styles involved in adolescent development include paternal overprotection, excessive interference, rejection and denial, and favoring subject and maternal punishment and severity, overprotection and excessive interference, and rejection and denial. These relationships may exist because family systems are the safest, healthiest, and most effective environments for the growth and development of adolescents, and parents' mismatched parenting styles can cause tension in parentchild relationships, family dysfunction, and family environment disharmony. The occurrence of these phenomena may reduce adolescents' dependence on their families and even weaken or cut off family relationships, creating an imbalance in the 
TABLE 4 | Bootstrap test for significance of the main effect size of the structural model.

\begin{tabular}{|c|c|c|c|c|c|}
\hline Runs & Paths & Standardized effect value & SE & $P$ & $95 \% \mathrm{Cl}$ \\
\hline 11 & Paternal parenting style $\rightarrow$ Social support $\rightarrow$ Drug abuse identification & 0.062 & 0.018 & 0.000 & {$[0.032,0.103]$} \\
\hline 12 & Maternal parenting style $\rightarrow$ Social support $\rightarrow$ Drug abuse identification & 0.031 & 0.017 & 0.036 & {$[0.002,0.069]$} \\
\hline D3 & Paternal parenting style $\rightarrow$ Drug abuse identification & 0.072 & 0.054 & 0.152 & {$[-0.028,0.169]$} \\
\hline D4 & Maternal parenting style $\rightarrow$ Drug abuse identification & 0.089 & 0.047 & 0.071 & {$[-0.008,0.176]$} \\
\hline
\end{tabular}

family ecosystem and inhibiting the healthy development of adolescents (Šumskas and Zaborskis, 2017; Liu and Visher, 2021). On the other hand, parental warmth and understanding, paternal punishment and severity, and maternal favoritism for participants are likely to be protective factors for adolescent drug abuse prevention (Garcia and Serra, 2019; Lukavska et al., 2020). The negative influence of parenting styles forces adolescent drug abusers to separate from the family environment (Kliewer and Zaharakis, 2014). Adolescent drug abusers will then seek a new environment and change their own development directions and goals. Social resources provide important support for the behavioral development of adolescents who take drugs under these circumstances.

\section{Mediating Role of Social Support}

As a risk factor for drug abuse, poor parenting styles cannot directly affect drug abuse identification but can affect drug abuse identification through the role of social support (Ryan et al., 2010; Tussey et al., 2021). It can be concluded that social support plays a mediating role between parenting styles and drug abuse identification, which means that parenting styles play an indirect role in drug abuse identification. The mechanisms of parenting styles, social support and drug abuse identification are summarized as follows. First, for the family, overprotection and excessive interference from parents, as well as the father favoring the subject, will enhance dependence on the family in the process of socialization, which may lead to a decline in objective support and degree of utilization of social support, as well as enhance drug abuse identification and increasing the likelihood of drug abuse. Second, over the course of a lifetime, rejection and denial from parents and severe punishment by mothers can reduce adolescents' family dependence (Čablová et al., 2014; Valente et al., 2020). Social support may be the main factor that affects the socialization of adolescents who use drugs, and a lack of social support may affect adolescent drug abuse identification (Fredrick et al., 2018). Insufficient objective support and low

TABLE $\mathbf{5}$ | Analysis of fit between adolescent drug abusers and non-drug abusers.

\begin{tabular}{|c|c|c|c|c|c|c|c|}
\hline Model & $x^{2}$ & $\chi^{2} / \mathrm{df}$ & IFI & TLI & GFI & AGFI & RMSEA \\
\hline Unconstrained & 694.261 & 4.339 & 0.885 & 0.848 & 0.860 & 0.790 & 0.075 \\
\hline $\begin{array}{l}\text { Measurement } \\
\text { weights }\end{array}$ & 766.907 & 4.408 & 0.872 & 0.845 & 0.850 & 0.792 & 0.076 \\
\hline $\begin{array}{l}\text { Structural } \\
\text { covariances }\end{array}$ & 837.541 & 4.679 & 0.851 & 0.810 & 0.827 & 0.768 & 0.086 \\
\hline $\begin{array}{l}\text { Measurement } \\
\text { residuals }\end{array}$ & 891.515 & 4.819 & 0.843 & 0.809 & 0.816 & 0.749 & 0.093 \\
\hline
\end{tabular}

degree of social support increase adolescents' access to drugs and the likelihood of adolescent drug abuse (Becoña et al., 2011; Rubio et al., 2020).

Therefore, social support plays an important role in helping explain and analyze the relationship between parenting styles and drug abuse. This result corroborates Bronfenbrenner's ecosystem theory. Adolescent drug abuse involves a complex process of interaction between family and social support (Eppler, 2019), mainly because family, as a proximal environment, greatly impacts the direction and effectiveness of adolescent behavioral development (Wolford et al., 2020; Cao et al., 2021). When excessive negative parenting styles manifest, resulting in insufficient family support, adolescents may seek new forms of support, and the focus of socialization may shift from family to peers or other social groups. A lack of social support will lead to the development of new models for adolescents to achieve a new balance (Mitrani et al., 2012; Feeney and Collins, 2015). In an environment with high drug abuse identification, adolescents are more inclined to enter drug abuse groups to integrate into the new environment. Furthermore, under the influence of the group, drug abuse identification is enhanced, which means that a pattern of adolescent drug abuse behavior is more likely to appear than other behaviors. Special attention is given to the negative correlation between social support and drug abuse identification, which provides a basis for the establishment of prevention or intervention systems from enhanced social support.

\section{Importance and Identification of the Mediating Role of Social Support}

This study demonstrates that the structural equation model presents a stable structure and invariability between groups and that parenting styles can predict drug abuse identification through social support. According to the presented comparison of social support for different types of adolescents, the social support of adolescent non-drug abusers $(M=40.934, S D=9.318$, $P<0.001)$ was found to be stronger than that of adolescent drug abusers $(M=37.198, S D=8.411, P<0.001)$. In particular, we found a significant difference between objective support $(P<0.001)$ and support utilization degree $(P<0.001)$. This indicates that positive social support encourages positive behavior for adolescents, and insufficient social support has a direct negative effect on adolescents' drug abuse identification.

Additionally, previous studies have focused on directly changing or optimizing parenting styles to change adolescent drug abuse while ignoring the mediating role of social support (Kopak et al., 2012; Szapocznik et al., 2012; Ramadhan et al., 2019). The limitations of previous studies can support new prevention and intervention strategies that can enhance the 


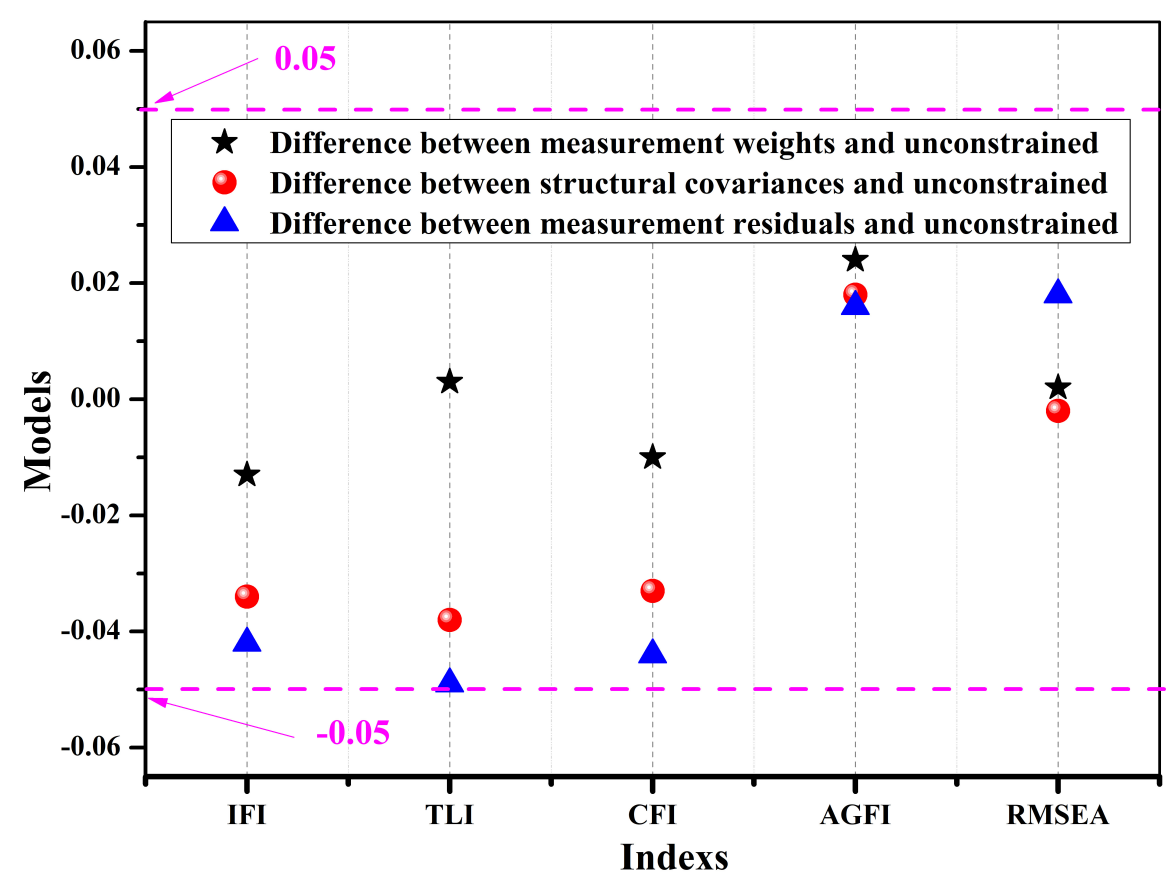

FIGURE 2 | Model invariant tests of adolescent drug abusers and non-abusers (Detla).

effectiveness of family education by adjusting social support, especially objective support and the utilization of social support. Families, society and adolescents form a closed ecosystem. When this ecosystem is damaged or unbalanced, adolescent drug abuse identification crises occur (Lian et al., 2016). Our results highlight the importance of adolescent drug abuse prevention and intervention strategies applying the following five strategies. First, antidrug agencies can increase social support, especially through the positive role of subjective support and support utilization degree, to control or restrain the negative factors such as excessive interferences, favoring subject, rejection and denial, and overprotection of fathers, and overprotection and excessive interference, rejection and denial, and punishment and severity of mothers. Meanwhile, antidrug agencies should also optimize and develop positive factors such as emotional warmth and understanding of parents, punishment and severity of fathers and favoriting subject of mothers, so as to control the development of parenting styles of adolescents toward a benign direction. Second, the negative and positive factors of adolescent drug abuse span multiple ecological levels of the family, society and other sectors, and there is an urgent need for multifaceted measures targeted at the family and society. A professional team composed of psychologists, social workers and therapists developed family-social support program based on the mediating role of social support. Through the intervention of social support and parenting style, especially the improvement of parental support, the program aims to jointly resist the negative factors leading to adolescent drug abuse by supervising the study and outdoor risky behavior of adolescents with different sexes, types and stages. Third, schools are the best place to start adolescent drug abuse programs. School-based anti-drug programs need to include family topics, which can enhance parenting skills (communication, rules, discipline, etc.), and communication within the family. Fourth, antidrug agencies should strengthen the development of joint antidrug projects with family and social support. And a diversified prevention system based in a systematic and governance concept must be developed. Finally, families and communities involved in the implementation process should follow laws and regulations, strengthen responsibility provisions and punishment measures, and create a green and drug-free growth environment for adolescents.

\section{Research Limitations and Prospects}

This study has some limitations. First, although the presented model can verify which facets of parenting styles can predict adolescent drug abuse identification, it is mostly applied based on horizontal studies and cannot determine causal relationships. Second, the mediating role of social support can well explain the correlations and mechanisms between parenting styles and drug abuse identification. However, there are many types of social support, leading to different associations with drug abuse identification without further differentiation. Third, in explaining the mediating role of parenting styles in drug abuse identification, social support is accompanied by changes in psychological states; therefore, corresponding physiological indexes can be considered in future studies. Fourth, the sample size is insufficient. In the follow-up study, we will increase the sample size to make the study more convincing and meaningful, and improve the promotion. Fifth, the indexes of structural equation model have certain limitations, and further optimization is needed. For instance, the above-mentioned physiological indexes are included 
in the study to further optimize the model. Finally, adolescent development emphasizes interactions between the individual and the situation. However, this study examined only the oneway prediction relationships between variables, and the cross-lag model will be used to explore two-way effects in the future.

Despite the shortcomings mentioned above, this study provides a detailed discussion of the relationships between parenting styles, social support, and adolescent drug abuse identification, and the results are relatively reliable, providing a reference for adolescent drug abuse prevention and intervention strategies.

\section{CONCLUSION}

To summarize, parenting styles, including maternal and paternal parenting styles, can significantly predict adolescent drug abuse behavior. Different parenting styles have different influencing mechanisms, further showing that poor parenting styles are a risk factor for adolescent drug abuse identification. Additionally, parenting styles can indirectly influence adolescent drug abuse identification through social support. The specific pathways involved are as follows: Paternal parenting style $\rightarrow$ Social support $\rightarrow$ Drug abuse identification and Maternal parenting style $\rightarrow$ Social support $\rightarrow$ Drug abuse identification. Social support plays a fully mediating role. However, the validation of the multi-group model shows that the structural model shows good adaptability and stability between adolescent drug abusers and non-drug

\section{REFERENCES}

Abbas, K., Xu, D., Li, S., and Baz, K. (2021). Health implications of household multidimensional energy poverty for women: a structural equation modeling technique. Energy Build. 234:110661. doi: 10.1016/j.enbuild.2020.110661

Asbrand, J., Hudson, J., Schmitz, J., and Tuschen-Caffier, B. (2017). Maternal parenting and child behaviour: an observational study of childhood social anxiety disorder. Cogn. Ther. Res. 41, 562-575. doi: 10.1007/s10608-0169828-3

Attar-Schwartz, S., Mishna, F., and Khoury-Kassabri, M. (2019). The role of classmates' social support, peer victimization and gender in externalizing and internalizing behaviors among Canadian youth. J. Child Fam. Stud. 28, 23352346. doi: 10.1007/s10826-017-0852-z

Azpiazu, L., Esnaola, I., and Sarasa, M. (2015). Capacidad predictiva del apoyo social en la inteligencia emocional de adolescentes. Eur. J. Educ. Psychol. 8, 23-29. doi: 10.1016/j.ejeps.2015.10.003

Baumrind, D. (2013). "Authoritative parenting revisited: history and current status," In Authoritative Parenting: Synthesizing Nurturance And Discipline For Optimal Child Development. eds R. E. Larzelere, A. S. Morris, and A. W. Harrist (Wahington: American Psychological Association), 11-34.

Becoña, E., Arrojo, M., López, A., Fernández del Río, E., López, F., Osorio, J., et al. (2011). Tienen una personalidad distinta los adolescentes consumidores de psicoestimulantes? Psicothema 23, 552-559.

Becoña, E., Martínez, Ú, Calafat, A., Juan, M., Duch, M., and Fernández-Hermida, J. R. (2012). How does family disorganization influence children's drug use? A review. Adicciones 24, 253-268.

Birtel, M. D., Wood, L., and Kempa, N. J. (2017). Stigma and social support in substance abuse: implications for mental health and well-being. Psychiatry Res. 252, 1-8. doi: 10.1016/j.psychres.2017.01.097

Buttram, M. E., Kurtz, S. P., and Surratt, H. L. (2013). Substance use and sexual risk mediated by social support among black men. J. Commun. Health 38, 62-69. doi: 10.1007/s10900-012-9582-8 abusers. This work provides a practical and theoretical basis for utilizing the mediating role of social support to optimize parenting styles and develop strategies for adolescent drug abuse prevention and intervention.

\section{DATA AVAILABILITY STATEMENT}

The original contributions presented in the study are included in the article/supplementary material, further inquiries can be directed to the corresponding author/s.

\section{AUTHOR CONTRIBUTIONS}

LL and BL conducted the conceptualization and methodology of the research study. WM was responsible for collecting and analyzing the data. LL completed the writing - original draft and formal analysis. All authors contributed to the article and approved the submitted version.

\section{FUNDING}

This work was supported by the Shandong Province Social Science Planning 2018 Project under Great (No. 18CYJ03) and Shandong Province Social Science PlannF17 Key Project under Great (No. 17BJYJ04).

Čablová, L., Pazderková, K., and Miovský, M. (2014). Parenting styles and alcohol use among children and adolescents: a systematic review. Drugs 21, 1-13. doi: 10.3109/09687637.2013.817536

Calafat, A., García, F., Juan, M., Becoña, E., and Fernández-Hermida, J. R. (2014). Which parenting style is more protective against adolescent substance use? Evidence within the European context. Drug Alcohol Depend. 138, 185-192. doi: 10.1016/j.drugalcdep.2014.02.705

Cambron, C., Catalano, R. F., and Hawkins, J. D. (2019). The social development model. Oxford Handbook Dev. Life Course Criminol. 191, 223-247. doi: 10.1093/ oxfordhb/9780190201371.013.13

Cao, M., Tian, Y., Lian, S., Yang, X., and Zhou, Z. (2021). Family socioeconomic status and adolescent depressive symptoms: a moderated mediation model. J. Child Fam. Stud. 30, 2652-2663. doi: 10.1007/s10826-021-02068-1

Chen, X., Liu, T., Luo, J., and Ren, S. (2020). Data for teenagers' stressor, mental health, coping style, social support, parenting style and self-efficacy in South China. Data Brief 29:105202. doi: 10.1016/j.dib.2020.105202

Clayborne, Z. M., Kingsbury, M., Sampasa-Kinyaga, H., Sikora, L., Lalande, K. M., and Colman, I. (2021). Parenting practices in childhood and depression, anxiety, and internalizing symptoms in adolescence: a systematic review. Soc. Psychiatry Psychiatric Epidemiol. 56, 619-638. doi: 10.1007/s00127-02001956-Z

Degenhardt, L., Stockings, E., Patton, G., Hall, W. D., and Lynskey, M. (2016). The increasing global health priority of substance use in young people. Lancet Psychiatry 3, 251-264. doi: 10.1016/S2215-0366(15)00508-8

Dembo, R., Briones-Robinson, R., Barrett, K. L., Winters, K. C., Ungaro, R., Karas, L., et al. (2015). Parenting practices among biological mothers of druginvolved truant youths: a latent profile analysis. J. Child Adolesc. Subst. Abuse 24, 282-294. doi: 10.1080/1067828X.2013.829011

Dumas, T. M., Ellis, W., and Litt, D. M. (2020). What does adolescent substance use look like during the COVID-19 pandemic? Examining changes in frequency, social contexts, and pandemic-related predictors. J. Adolesc. Health 67, 354-361. doi: 10.1016/j.jadohealth.2020.06.018 
Emerson, R. W. (2015). Causation and Pearson's correlation coefficient. J. Vis. Impair. Blindness 109, 242-244. doi: 10.1177/0145482X1510900311

Eppler, C. (2019). "Ecosystem in family systems theory," in Encyclopedia of Couple and Family Therapy eds J. L. Lebow, A. L. Chambers, and D. C. Breunlin (Cham: Springer), 828-832. doi: 10.1007/978-3-319-49425-8

Feeney, B. C., and Collins, N. L. (2015). A new look at social support: a theoretical perspective on thriving through relationships. Pers. Soc. Psychol. Rev. 19, 113-147. doi: 10.1177/1088868314544222

Fernandez-Hermida, J. R., Calafat, A., Becoña, E., Tsertsvadze, A., and Foxcroft, D. R. (2012). Assessment of generalizability, applicability and predictability (GAP) for evaluating external validity in studies of universal family-based prevention of alcohol misuse in young people: systematic methodological review of randomized controlled trials. Addiction 107, 1570-1579. doi: 10.1111/ j.1360-0443.2012.03867.x

Fredrick, S. S., Demaray, M. K., Malecki, C. K., and Dorio, N. B. (2018). Can social support buffer the association between depression and suicidal ideation in adolescent boys and girls? Psychol. Sch. 55, 490-505. doi: 10.1002/pits. 22125

Garcia, O. F., and Serra, E. (2019). Raising children with poor school performance: parenting styles and short-and long-term consequences for adolescent and adult development. Int. J. Environ. Res. Public Health 16:1089. doi: 10.3390/ ijerph16071089

Garcia, O. F., Serra, E., Zacares, J. J., Calafat, A., and Garcia, F. (2020). Alcohol use and abuse and motivations for drinking and non-drinking among Spanish adolescents: do we know enough when we know parenting style? Psychol. Health 35, 645-664. doi: 10.1080/08870446.2019.1675660

Gázquez, J. J., del Carmen Pérez-Fuentes, M., del Mar Molero, M., Martín, A. B. B., Martínez, Á. M., and Sánchez-Marchán, C. (2016). Drug use in adolescents in relation to social support and reactive and proactive aggressive behavior. Psicothema 28, 318-322. doi: 10.7334/psicothema2015.327

Go, V. F., Latkin, C., Le Minh, N., Frangakis, C., Ha, T. V., Sripaipan, T., et al. (2016). Variations in the role of social support on disclosure among newlydiagnosed HIV-infected people who inject drugs in Vietnam. AIDS Behav. 20, 155-164. doi: 10.1007/s10461-015-1063-5

Guy-Evans, O. (2020). Bronfenbrenner's Ecological Systems Theory. Available Online at: www.simplypsychology.org/Bronfenbrenner.html [accessed Nov 09, 2020].

Hall, W. D., Patton, G., Stockings, E., Weier, M., Lynskey, M., Morley, K. I., et al. (2016). Why young people's substance use matters for global health. Lancet Psychiatry 3, 265-279. doi: 10.1016/S2215-0366(16)00013-4

Holt-Lunstad, J., and Uchino, B. N. (2015). "Social support and health," in Health Behavior: Theory, Research And Practice, eds K. Glanz, B. K. Rimer, and K. V. Viswanath (San Francisco: Jossey-Bass/Wiley), 183-204.

Hummel, A., Shelton, K. H., Heron, J., Moore, L., and van den Bree, M. B. (2013). A systematic review of the relationships between family functioning, pubertal timing and adolescent substance use. Addiction 108, 487-496. doi: 10.1111/add. 12055

Irles, D. L., Sánchez, J. P. E., Perona, V. C., and Burkhart, G. (2013). Prevención familiar del consumo de drogas en Europa: una revisión crítica de los programas contenidos en EDDRA. Adicciones 25, 226-234. doi: 10.20882/adicciones.50

James, A., James, C., and Thwaites, T. (2013). The brain effects of cannabis in healthy adolescents and in adolescents with schizophrenia: a systematic review. Psychiatry Res. 214, 181-189. doi: 10.1016/j.pscychresns.2013.07.012

Karaer, Y., and Akdemir, D. (2019). Parenting styles, perceived social support and emotion regulation in adolescents with internet addiction. Compr. Psychiatry 92, 22-27. doi: 10.1016/j.comppsych.2019.03.003

Ke, D., Lu, D., Huang, Y., Bi, F., Wang, M., Chen, X., et al. (2019). Quality of life among people newly diagnosed with HIV/AIDS. Chin. Assoc. Mental Health 27, 582-585. doi: 10.16128/j.cnki.1005-3611.2019.03.031

Kepple, N. J. (2017). The complex nature of parental substance use: examining past year and prior use behaviors as correlates of child maltreatment frequency. Subst. Use Misuse 52, 811-821. doi: 10.1080/10826084.2016.1253747

Kliewer, W., and Zaharakis, N. (2014). "Family-based models of drug etiology," in Parenting And Teen Drug Use, eds L. M. Scheier and W. B. Hansen (Oxford: Oxford University Press), 37-61.

Kopak, A. M., Chen, A. C. C., Haas, S. A., and Gillmore, M. R. (2012). The importance of family factors to protect against substance use related problems among Mexican heritage and White youth. Drug Alcohol Depend. 124, 34-41. doi: 10.1016/j.drugalcdep.2011.12.004
Lian, L., You, X., Huang, J., and Yang, R. (2016). Who overuses smartphones? Roles of virtues and parenting style in smartphone addiction among Chinese college students. Comput. Hum. Behav. 65, 92-99. doi: 10.1016/j.chb.2016.08.027

Lippold, M. A., Greenberg, M. T., and Collins, L. M. (2014). Youths' substance use and changes in parental knowledge-related behaviors during middle school: a person-oriented approach. J. Youth Adolesc. 43, 729-744. doi: 10.1007/s10964013-0010-x

Liu, L., and Visher, C. A. (2021). The roles of family, community, and services in the prevention of illicit drug use: findings from a sample of released prisoners. J. Drug Issues 51, 358-375. doi: 10.1177/0022042620984770

Liu, Y., Li, S., He, Y., Wang, D., and Yang, B. (2021). Eliminating threat or venting rage? The relationship between narcissism and aggression in violent offenders. Acta Psychol. Sin. 53, 244-258. doi: 10.3724/SP.J.1041.2021.00244

Lukavska, K., Vacek, J., and Gabhelik, R. (2020). The effects of parental control and warmth on problematic internet use in adolescents: a prospective cohort study. J. Behav. Addict. 9, 664-675. doi: 10.1556/2006.2020.00068

Malta, D. C., Mascarenhas, M. D. M., Porto, D. L., Duarte, E. A., Sardinha, L. M., Barreto, S. M., et al. (2011). Prevalence of alcohol and drug consumption among adolescents: data analysis of the National Survey of School Health. Rev. Brasil. Epidemiol. 14, 136-146. doi: 10.1590/S1415-790X2011000500014

Martínez-Loredo, V., Fernández-Artamendi, S., Weidberg, S., Pericot, I., LópezNúñez, C., Fernández-Hermida, J. R., et al. (2016). Parenting styles and alcohol use among adolescents: a longitudinal study. Eur. J. Investig. Health Psychol. Educ. 6, 27-36. doi: 10.1989/ejihpe.v6il.146

Massah, O., Azkhosh, M., Azami, Y., Goodiny, A. A., Doostian, Y., and Mousavi, S. H. (2017). Students tendency toward illicit drug use: the role of perceived social support and family function in Iran. Iran. J. Psychiatry Behav. Sci. 11:e8314. doi: 10.17795/ijpbs.8314

Matejevic, M., Jovanovic, D., and Lazarevic, V. (2014). Functionality of family relationships and parenting style in families of adolescents with substance abuse problems. Proc. Soc. Behav. Sci. 128, 281-287. doi: 10.1016/j.sbspro.2014.03.157

Mitrani, V. B., McCabe, B. E., Burns, M. J., and Feaster, D. J. (2012). Family mechanisms of structural ecosystems therapy for HIV-seropositive women in drug recovery. Health Psychol. 31, 591-600. doi: 10.1037/a0028672

Mo, P. K., Chen, X., Lam, E. H., Li, J., Kahler, C. W., and Lau, J. T. (2020). The moderating role of social support on the relationship between anxiety, stigma, and intention to use illicit drugs among HIV-positive men who have sex with men. AIDS Behav. 24, 55-64. doi: 10.1007/s10461-019-02719-x

Morse, D. S., Cerulli, C., Bedell, P., Wilson, J. L., Thomas, K., Mittal, M., et al. (2014). Meeting health and psychological needs of women in drug treatment court. J. Subst. Abuse Treat. 46, 150-157. doi: 10.1016/j.jsat.2013.08.017

Mueller, R. O., and Hancock, G. R. (2019). Structural Equation Modeling. Milton Park: Routledge/Taylor and Francis Group.

Özdemir, M., and Koutakis, N. (2016). Does promoting parents' negative attitudes to underage drinking reduce adolescents' drinking? The mediating process and moderators of the effects of the Örebro Prevention Programme. Addiction 111, 263-271. doi: 10.1111/add.13177

Patte, K. A., Qian, W., and Leatherdale, S. T. (2017). Marijuana and alcohol use as predictors of academic achievement: a longitudinal analysis among youth in the COMPASS study. J. Sch. Health 87, 310-318. doi: 10.1111/josh.12498

Perris, C., and Andersson, P. (2000). Experiences of parental rearing and patterns of attachment in adulthood. Clin. Psychol. Psychother. Int. J. Theory Pract. 7, 279-288. doi: 10.1002/1099-0879(200010)7:4<279::AID-CPP260>3.0.CO;2-7

Perruci, L. G., Diehl, A., Da Silveira, B. V., Teixeira, J. A., Souza, J., Miasso, A. I., et al. (2021). The emotional and psychiatric problems of adolescents on parole whose parents are substance users: a Brazilian cross-sectional study. J. Child Health Care 25, 253-267. doi: 10.1177/1367493520925661

Ramadhan, I., Keliat, B. A., and Wardani, I. Y. (2019). Assertiveness training and family psychoeducational therapies on adolescents mental resilience in the prevention of drug use in boarding schools. Enferm. Clin. 29, 326-330. doi: 10.1016/j.enfcli.2019.04.040

Rapee, R. M., Peters, L., Carpenter, L., and Gaston, J. E. (2015). The Yin and Yang of support from significant others: influence of general social support and partner support of avoidance in the context of treatment for social anxiety disorder. Behav. Res. Ther. 69, 40-47. doi: 10.1016/j.brat.2015.03.012

Reis, L. F., Surkan, P. J., Valente, J. Y., Bertolla, M. H., and Sanchez, Z. M. (2020). Factors associated with early sexual initiation and unsafe sex in adolescents: substance use and parenting style. J. Adolesc. 79, 128-135. doi: 10.1016/j. adolescence.2019.12.015 
Ribeiro, M., Perrenoud, L. O., Duailibi, S., Duailibi, L. B., Madruga, C., Marques, A. C. P. R., et al. (2013). The Brazilian drug policy situation: the public health approach based on research undertaken in a developing country. Public Health Rev. 35:7. doi: 10.1007/BF03391706

Rubio, A., Oyanedel, J. C., Cancino, F., Benavente, L., Céspedes, C., Zisis, C., et al. (2020). Social support and substance use as moderators of the relationship between depressive symptoms and suicidal ideation in adolescents. Front. Psychol. 11:539165. doi: 10.3389/fpsyg.2020.539165

Rudolph, A. E., Davis, W. W., Quan, V. M., Ha, T. V., Minh, N. L., Gregowski, A., et al. (2012). Perceptions of community-and family-level injection drug user (IDU)-and HIV-related stigma, disclosure decisions and experiences with layered stigma among HIV-positive IDUs in Vietnam. AIDS Care 24, 239-244. doi: 10.1080/09540121.2011.596517

Ryan, S. M., Jorm, A. F., and Lubman, D. I. (2010). Parenting factors associated with reduced adolescent alcohol use: a systematic review of longitudinal studies. Aust. N. Z. J. Psychiatry 44, 774-783. doi: 10.1080/00048674.2010.501759

Sanchez, Z. M., Valente, J. Y., Sanudo, A., Pereira, A. P. D., Schneider, D. R., and Andreoni, S. (2018). Effectiveness evaluation of the school-based drug prevention program\# Tamojunto in Brazil: 21-month follow-up of a randomized controlled trial. Int. J. Drug Policy 60, 10-17. doi: 10.1016/j.drugpo. 2018.07.006

Song, J. M., and Fan, H. Y. (2013). A meta-analysis of the relationship between social support and subjective well-being. Adv. Psychol. Sci. 21, 1357-1370. doi: 10.3724/SP.J.1042.2013.01357

Šumskas, L., and Zaborskis, A. (2017). Family social environment and parenting predictors of alcohol use among adolescents in Lithuania. Int. J. Environ. Res. Public Health 14:1037. doi: 10.3390/ijerph14091037

Szapocznik, J., Schwartz, S. J., Muir, J. A., and Brown, C. H. (2012). Brief strategic family therapy: an intervention to reduce adolescent risk behavior. Couple Family Psychol. 1, 134-145. doi: 10.1037/a0029002

Takahara, A. H., Furino, V., Marques, A. C., Zerbetto, S., and Furino, F. (2017). Relações familiares, álcool e outras drogas: uma revisão integrativa. Rev. APS 20, 434-443. doi: 10.34019/1809-8363.2017.v20.15999

Thompson, E. A., Connelly, C. D., Thomas-Jones, D., and Eggert, L. L. (2013). School difficulties and co-occurring health risk factors: substance use, aggression, depression, and suicidal behaviors. J. Child Adolesc. Psychiatric Nurs. 26, 74-84. doi: 10.1111/jcap.12026

Tremblay, M., Baydala, L., Khan, M., Currie, C., Morley, K., Burkholder, C., et al. (2020). Primary substance use prevention programs for children and youth: a systematic review. Pediatrics 146:e20192747. doi: 10.1542/peds.2019-2747

Trucco, E. M. (2020). A review of psychosocial factors linked to adolescent substance use. Pharmacol. Biochem. Behav. 196:172969. doi: 10.1016/j.pbb.2020. 172969

Tussey, B. E., Tyler, K. A., and Simons, L. G. (2021). Poor parenting, attachment style, and dating violence perpetration among college students. J. Interpers. Viol. 36, 2097-2116. doi: 10.1177/0886260518760017

Uchino, B. N., Bowen, K., de Grey, R. K., Mikel, J., and Fisher, E. B. (2018). "Social support and physical health: models, mechanisms, and opportunities," in Principles And Concepts Of Behavioral Medicine, eds E. Fisher, L. Cameron, A. Christensen, U. Ehlert, Y. Guo, B. Oldenburg, et al. (New York: Springer), 341-372. doi: 10.1007/978-0-387-93826-4_12
UNODC (2021). United Nations Office On Drugs And Crime Vienna Annual Report Covering Activities During. Vienna: UNODC, 1-10.

Valente, J. Y., Cogo-Moreira, H., and Sanchez, Z. M. (2017). Gradient of association between parenting styles and patterns of drug use in adolescence: a latent class analysis. Drug Alcohol Depend. 180, 272-278. doi: 10.1016/j.drugalcdep.2017. 08.015

Valente, J. Y., Cogo-Moreira, H., and Sanchez, Z. M. (2019). Predicting latent classes of drug use among adolescents through parental alcohol use and parental style: a longitudinal study. Soc. Psychiatry Psychiatric Epidemiol. 54, 455-467. doi: 10.1007/s00127-018-1645-4

Valente, J. Y., Cogo-Moreira, H., and Sanchez, Z. M. (2020). Evaluating the effects of parenting styles dimensions on adolescent drug use: secondary analysis of\# Tamojunto randomized controlled trial. Eur. Child Adolesc. Psychiatry 29, 979-987. doi: 10.1007/s00787-019-01410-9

Varvil-Weld, L., Scaglione, N., Cleveland, M. J., Mallett, K. A., Turrisi, R., and Abar, C. C. (2014). Optimizing timing and dosage: does parent type moderate the effects of variations of a parent-based intervention to reduce college student drinking? Prevent. Sci. 15, 94-102. doi: 10.1007/s11121-012-0356-4

Weng, M. (2020). Exploration of psychological mechanism model of adolescent drug abuse based on multi-group mediation analysis. Tianjin Normal Univ. 8, 15-18. doi: 10.27363/d.cnki.gtsfu.2020.000220

Wolford, S. N., Darling, C. A., Rehm, M., and Cui, M. (2020). Examining parental internal processes associated with indulgent parenting: a thematic analysis. J. Child Family Stud. 29, 660-675. doi: 10.1007/s10826-019-01612-4

Zhang, S., Lim, Y., Boyas, J. F., and Burlaka, V. (2020). Family structure and youth illicit drug use, use disorder, and treatment services utilization. Child. Youth Serv. Rev. 111:104880. doi: 10.1016/j.childyouth.2020.104880

Zhang, S. Y., and Demant, J. (2021). Effects of self-control, drug-use peers and family attachment on drug use among Chinese users: a gender-specific analysis. Drug Alcohol Rev. 40, 1369-1376. doi: 10.1111/dar.13295

Zrour, C., Naja, W., Chahoud, M., Halabi, A., Badaoui, A., and Haddad, R. (2021). Parenting styles and psychiatric profile of parents of adult substance use disorder patients: cross-sectional study. Int. J. Ment. Health Addict. 7, 1-16. doi: 10.1007/s11469-021-00554-7

Conflict of Interest: The authors declare that the research was conducted in the absence of any commercial or financial relationships that could be construed as a potential conflict of interest.

Publisher's Note: All claims expressed in this article are solely those of the authors and do not necessarily represent those of their affiliated organizations, or those of the publisher, the editors and the reviewers. Any product that may be evaluated in this article, or claim that may be made by its manufacturer, is not guaranteed or endorsed by the publisher.

Copyright (c) 2022 Liu, Meng and Liu. This is an open-access article distributed under the terms of the Creative Commons Attribution License (CC BY). The use, distribution or reproduction in other forums is permitted, provided the original author(s) and the copyright owner(s) are credited and that the original publication in this journal is cited, in accordance with accepted academic practice. No use, distribution or reproduction is permitted which does not comply with these terms. 